visual presentation, particularly in the field of professional education and this offering is a fairly recent example. As a now retired, long-serving, lay member of the mental health review tribunal (MHRT), I was interested to see what this combined product had to offer. However, before doing so, a word or two concerning the context may be helpful. When the Human Rights Act came into force in October 2000, it was hailed by the Government as an important means of giving citizens the right to challenge the activities of the State through the courts. At the time of its inception, some mental health lawyers thought the impact of the Act would provide considerable opportunities for challenge (a view put forward in the video). A more balanced view indicated that if tribunals followed the 'rules' correctly, little litigation would be likely to ensue. This seems to have been the case, since (as far as I have been able to ascertain informally) only a few cases await judicial review and these seem mainly concerned with matters of interpretation disclosure and delays. The booklet, of some 30 pages, to be read in conjunction with the video, deals with 'The Law of European Convention'; 'Possible Challenges'; 'Possible Defences'; 'Relevant Parts of the Human Rights Act'; 'Schedule 1 of the Act' and 'Judgments of the European Court of Human Rights'. I found the section devoted to the Law of the European Convention the most interesting. The other sections will be of most interest (and comprehension) to lawyers! I viewed the video in the company of my daughter (who is a lawyer, but does not specialise in mental health law) and her partner, who is a retired educationalist. The copy we received was of poor sound quality (I tried it on two different video machines to make sure it was the video and not the equipment). The introductory musical 'jingle' was very off-putting. However, for the most part, the presentation by four professionals (three experienced lawyers and an advocacy manager) was competent enough and easy to 'access'. However, the production's biggest weak ness was the fact that it was made prior to the actual implementation of the Act. It therefore really needs updating. Even allowing for the high cost of producing professional videos, it is very expensive. I do not imagine individuals will think they can afford it for their personal use, but training bodies may feel they should buy it - allowing for budgetary constraints. The pack is not without its merits and I shall probably donate mine to our regional tribunal office as a belated leaving present -1 retired a year ago!

Herschel Prins Loughborough, NottinghamTrent and Leicester Universities

\section{National Service Framework for Older People}

London: Department of Health. 2001. 194 pp. Free of charge.

This National Service Framework (NSF) is welcome. It confirms that the health and welfare of older people is to be addressed as a priority - and comes only fourth in the series of such publications - after cancer, coronary heart disease and mental illness. All the publications intend to improve services and reduce inequalities between services received by different groups in different parts of England.

Old age psychiatrists, and other professionals, have waited with eager anticipation for this publication's delivery, uncomfortable that older people and people with dementia had been excluded from the otherwise excellent NSF for Mental Illness. There were delays in delivery and 'false start' announcements of publication before Christmas 2000. All this added to the excitement and sense of moment. Momentous it has indeed proved, and interest has been heightened by controversy, antipathy and expressions of doubt from senior sources within the establishment of care of the elderly.

A great deal of work was undertaken by expert working groups - including members with diverging views. Their contributions were interpreted by civil servants and subject to the stamp of Professor Philp who was appointed Tzar toward the end of the process. These editorial intrusions have irritated some of the figures from the working groups, but they have resulted in a brave and fairly cohesive document, which will help us improve the health of older people and the services they receive. Our society and our government stigmatises and discriminates against older people, particularly those with mental illness and from disadvantaged groups and localities. This phenomenon is nailed.

Some health care professionals have sought to interpret 'equity' for old people in terms of admission to the same acute hospital wards as younger people. This false vision of equity is confronted.

Older people with serious mental illnesses of all kinds, including those who survive into later life with chronic or relapsing disorders, require the same discipline and quality of care guaranteed to younger people with mental illness by the NSF for Mental Illness.

The exclusion of older people from consideration by the NSF for Mental Illness is declared, politely, to be unacceptable.

A comprehensive framework ranges from health promotion to continuing and terminal care across the boundaries of personal, family, voluntary, social and health service responsibilities - pretty thrilling for a Department of Health publication. The practical implication of the NSF for Older People is the presence of a hierarchical strategy of implementation: national, regional and local mental health professionals are involved at all levels and should be included in working groups for all eight standards (and the group considering medication).

The process and its outcome will bond old age psychiatry more securely within health care for the elderly. Its interface with general psychiatry will benefit from clarification, informed by a determination that the best interests of individual patients and their families remain paramount

David Jolley Division of Old Age Psychiatry, Penn Hospital, Penn Road, Wolverhampton, West Midlands WV4 5HN

\section{Individual Statement Questions for MRCPsych Part 1}

By Maju Mathews. London: Royal Society of Medicine Press. 2002. 105 pp. $£ 14.95$

ISBN: 1-85315-505-5

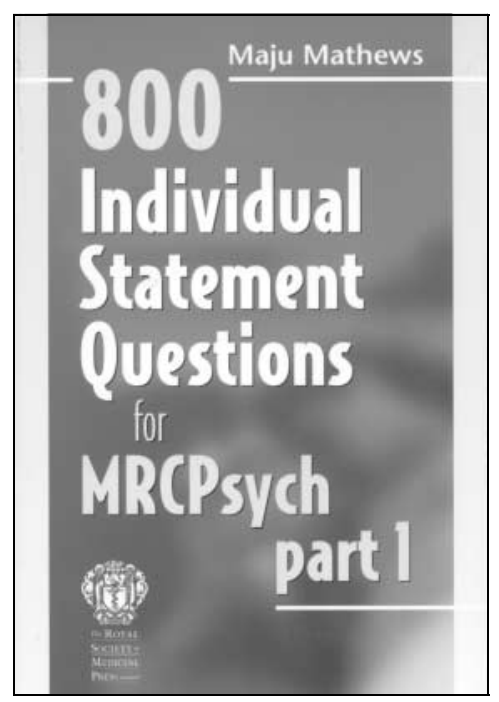

The multiple choice questions (MCQs) in both parts of the MRCPsych examination used to incite violence in hundreds of candidates who were unlucky enough to have to make sense of them. They seemed to be either excruciatingly obscure or so vaguely worded with 'clues', such as 'commonly', 'frequently', or 'not entirely unusual on the third Monday of an unusual month. ...', so as to be only understandable by James Joyce. And no one understands James Joyce!

Maju Mathews has tailored his book to the new MRCPsych Part I examination format. The book consists of four separate papers. A paper comprises 200 statements, each of which is answered as true or false.

Developing MCQ examination papers is a real headache. Getting the balance between the questions that a buffoon 
could answer and those that an expert would struggle with is no mean feat. My marks on the four papers ranged from $77 \%$ to $82 \%$. I am 4 years away from the MRCPsych Part II hurdle so, in my opinion, the papers seemed too easy, even though the pass mark will be raised because of the demise of negative marking. I asked some of my senior house officer colleagues to peruse the questions. They felt that the difficulty matched those seen at the recent MCQ paper in Autumn 2001.

The questions are unambiguous and seem fair but I do have a suspicion that they are too candidate-friendly. And $\mathrm{f} 14.95$ is not an inconsiderable sum for four MCQ papers. That said, there do not seem to be many such MCQ books around and you will probably get an ego boost from your score.

Navjot Ahluwalia

\section{The Experience of Alzheimer's Disease: Life Through aTangled Veil}

By Steven R Sabat. Oxford: Blackwell. 2001. 361 pp. f50.00 (hb) f16.99 (pb). ISBN: $063126650(\mathrm{hb}) ; 0631216669(\mathrm{pb})$

'A middle aged man realises his father is ill. The man tells his son it is time to take his grandfather to the top of the mountain to die. Father and son sit the old man in a wheel chair and move him

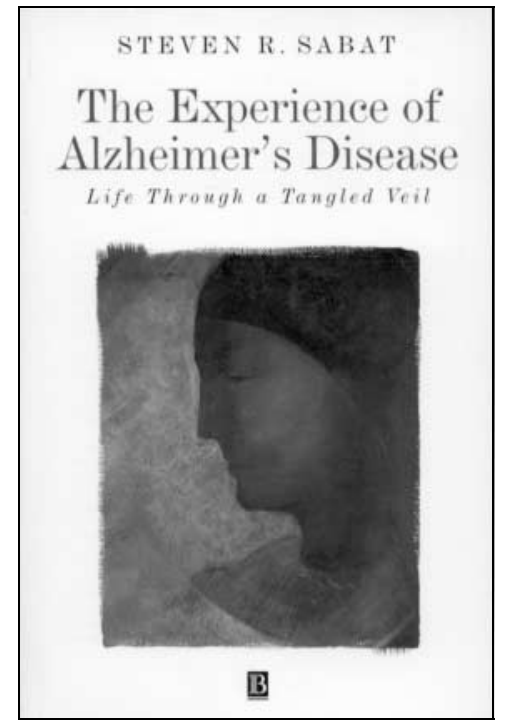

slowly up the mountain top where they will push him over the edge so that he can speedily meet his death.'

Sabat has written a complex, thoughtprovoking book which aims to give some insight into the subjective experience of Alzheimer's disease. He has drawn on his research experience working with patients who have the disease, giving detailed transcriptions of their conversations with an analysis of the content. He places the conversations in context to provide understanding amid apparent fragmentary speech and incomprehensible behaviour.

Sabat gently challenges the scientific and mental model of how Alzheimer's disease is identified and measured, in particular the traditional focus on deficit and pathology. He suggests there is value in individual experience rather than scientific averages without dismissing evidence-based medical principles. He invites a different viewpoint to reduce stigmatising and dysfunctional attitudes towards people with the disease. He asks us to focus on strengths not weaknesses, and to consider humanistic management rather than standard conventional 'palliative' care. He describes complicated philosophical, psychological and social construct theories to support his viewpoints. It is not a light read.

The book is interspersed with the voices of Alzheimer's disease patients and Sabat displays warmth, empathy and respect for the individuals described. The progression of their disease is clear through the narrative of the book and the outcome is no cliff-hanger. Ultimately, Sabat personalises Alzheimer's disease and confronts us with a need to change how we view people with the disease and how we can improve services to support them.

'Just as the man is about to push his father over the precipice his son calls out to him urgently, "don't let go of the wheelchair". The man turns to his son and asks for an explanation. His son tells him, "we are going to need it for you some day".'

R Clafferty Consultant Psychiatrist, Forth Valley Primary Care NHS Trust, Old Denny Road, Larbert FK5 4SD, UK

\section{miscellany}

\section{Flexible working for doctors}

The Flexible Careers Scheme (FCS) was developed as part of the Improving Working Lives for Doctors initiative. The scheme helps doctors maintain their careers by providing more centrally funded opportunities to work part time and have temporary career breaks. The Flexible Careers Scheme funds doctors who are able to work up to $49 \%$ of full time. In each case the scheme is adapted to individual circumstances and provides sufficient medical/clinical practice for revalidation purposes. The scheme helps doctors in the training grades, career grade doctors, returners and doctors nearing retirement. Some of the benefits of the scheme include: central funding to pump-prime the creation of more flexible part-time work arrangements including annualised hours and job shares; a fixed annual amount paid to the doctor to contribute towards professional expenses; access to the NHS pension scheme and to the same employment rights as other colleagues; and an exit strategy for moving on after being on the FCS. For further information or to apply to join, please contact NHS Professionals (Tel: 08456060 345) 